Article

\title{
Development of Selenium Nanoparticle Based Agriculture Sensor for Heavy Metal Toxicity Detection
}

\author{
Faheem Ahmed ${ }^{1, *}$, Sourabh Dwivedi ${ }^{2}{ }^{\circ}$, Nagih M. Shaalan $\left.{ }^{1,3}{ }^{(}\right)$, Shalendra Kumar ${ }^{1,4} \oplus^{(0}$, \\ Nishat Arshi ${ }^{5}$, Adil Alshoaibi ${ }^{1}$ (D) and Fohad Mabood Husain ${ }^{6}$ \\ 1 Department of Physics, College of Science, King Faisal University, P.O. Box 400, Al-Ahsa 31982, Saudi Arabia; \\ nmohammed@kfu.edu.sa (N.M.S.); sjagdish@kfu.edu.sa (S.K.); adshoaibi@kfu.edu.sa (A.A.) \\ 2 Department of Applied Physics, Aligarh Muslim University, Aligarh 202002, India; sourabh25june@gmail.com \\ 3 Physics Department, Faculty of Science, Assiut University, Assiut 71516, Egypt \\ 4 Department of Physics, School of Engineering, University of Petroleum \& Energy Studies, \\ Dehradun 248007, India \\ 5 Department of Basic Sciences, Preparatory Year Deanship, King Faisal University, P.O. Box 400, \\ Al-Ahsa 31982, Saudi Arabia; nshastri@kfu.edu.sa \\ 6 Department of Food Science and Nutrition, King Saud University, Riyadh 11451, Saudi Arabia; \\ fhusain@ksu.edu.sa \\ * Correspondence: fahmed@kfu.edu.sa; Tel./Fax: +966-013589-6900
}

Received: 16 October 2020; Accepted: 3 December 2020; Published: 8 December 2020

check for updates

\begin{abstract}
The presence of heavy metals in increased concentrations in the environment has become a global environmental concern. This rapid increase in heavy metals in the environment is attributed to enhanced industrial and mining activities. Metal ions possess a lengthy half-life and property to bioaccumulate, are non-biodegradable and, thus, are a threat to the human health. A number of conventional spectroscopic and chromatographic techniques are being used for the detection of heavy metals, but these suffer from various limitations. Nano-based sensors have emerged as potential candidates for the sensitive and selective detection of heavy metals. Thus, the present study was focused on the synthesis of selenium nanoparticles (SeNPs) by using selenite-reducing bacteria in the development of a heavy metal toxicity biosensor. During the biosynthesis of selenium nanoparticles, supernatants of the overnight-grown culture were treated with $\mathrm{Na}_{2} \mathrm{SeO}_{3}{ }^{2-}$ and incubated for $24 \mathrm{~h}$ at $37^{\circ} \mathrm{C}$. The as-synthesized nanoparticles were characterized by UV-Vis spectroscopy, X-ray diffraction (XRD), Fourier transform infrared (FTIR) and transmission electron microscopy (TEM) analyses. XRD and TEM results confirmed the formation of SeNPs in sizes ranging from 35 to $40 \mathrm{~nm}$, with face-centered cubic (FCC) structures. The bioreduction process and validation of the formation of SeNPs was further confirmed by FTIR studies. The reduction in the biosynthesis of SeNPs using bacterial metabolite due to heavy metal cytotoxicity was analyzed by the colorimetric bioassay (SE Assay). The inhibition of selenite reduction and loss of red color in the presence of heavy metals may serve as a biosensor for heavy metal toxicity analysis. Thus, this biosensor development is aimed at improving the sensitivity and specificity of analytic detection.
\end{abstract}

Keywords: biosynthesis; heavy metal toxicity; fluorescence; nano-biosensor; XRD

\section{Introduction}

In recent decades, the continuous release of heavy metals into natural water bodies has become globally prevalent. The toxicity of heavy metals is becoming a serious threat to humans and the environment. Due to improper waste management, heavy metals are contaminating agricultural soil because of their continuous use in industrial processes. Consequently, these contaminations cause alterations in biochemical cycles and modify biological macromolecules [1]. 
Moreover, most heavy metals are toxic and carcinogenic in nature, even at very low concentrations. Heavy metals do not undergo biodegradation and, hence, accumulate in the food chain and become deleterious to the environment, as well as human health [2]. Therefore, it is essential to study the presence of heavy metals present in the environment, food, water, and other biological systems [3].

Conventional methods used for the detection of heavy metals include atomic absorption spectroscopy, UV-visible spectroscopy, inductively coupled plasma mass spectroscopy, and chromatographic techniques. These techniques, though sensitive and selective, are sophisticated and costly. In addition, it requires a long time for measurement, complicated sample collection, pretreatment (pre-concentration), and is not portable for on-site application [4-6]. A number of methods have been developed for the detection of heavy/toxic metals based on sensors. Among the various new technologies, chemical and optical nano-sensors are an emerging technology to detect toxic heavy metals. Minni et al. [4] developed a biosensor that is capable of detecting $\mathrm{Ni}$ (II) at the range of $0.03-0.68 \mathrm{nM}$, with a response time of $1.5 \mathrm{~min}$. The developed system has a reliability of $91.5 \%$ and $90.6 \%$ for the samples and could possibly replace the existing conventional analysis techniques.

In another work, Li et al. [5] fabricated a methylene blue-mediated enzyme biosensor for the detection of inhibitors, including mercury(II), mercury(I), methylmercury, and the mercury-glutathione complex. Mercury compounds were assayed amperometrically with the detection limits of $0.1 \mathrm{ng}$ $\mathrm{mL}^{-1} \mathrm{Hg}$ for $\mathrm{HgCl}_{2}$ and methylmercury, $0.2 \mathrm{ng} \mathrm{mL}^{-1} \mathrm{Hg}$ for $\mathrm{Hg}_{2}\left(\mathrm{NO}_{3}\right)_{2}$, and $1.7 \mathrm{ng} \mathrm{mL} \mathrm{Hg}^{-1} \mathrm{Hg}$ for the mercury-glutathione complex. This has encouraged us to synthesize a low-cost, less time-consuming, and portable platform for detection of the toxicity of heavy metals.

Recently, the development of nanotechnology has opened new opportunities for the detection of heavy metals using nano-sensors. These nano-sensors have gained attention due to their ease of preparation, enhanced detection limit, and on-site application. Several nano-sensors have been developed so far using nanomaterials synthesized from green or chemical methods [7-9]. Nanomaterial-based sensors possess high surface reactivity, a large surface area, strong adsorption capacity, and enhanced catalytic efficiency, making them a potential candidate for heavy metal detection [7]. Various nanomaterials, including metal and metal oxide nanoparticles, nanocomposites, carbon-based nanomaterials, etc., have been used to fabricate sensors for heavy metal detection [10]. Owing to their size-dependent properties and high degree of functionality, nano-sensors exhibit increased sensitivity and selectivity [8]. Thus, nanoparticle-based sensors for heavy metal detection may be the way forward.

Ravi et al. [9] demonstrated a green and sustainable procedure by using orange and lemon extracts for the reduction of Ag and Au ions into simple metal NPs. Devnani and Satsangee [11] evaluated a method for electrochemical sensing of metals through AuNPs synthesized via anthocyanin-capped carbon paste electrode. Regardless of the advantages of metal nanoparticles, the cost and synthesis conditions associated with their preparation are the major drawbacks to their use. Thus, the development of an ecofriendly biogenic process for the preparation of potentially valuable nanoparticles is needed.

Selenium is generally found in the earth's crust, and the metal-reducing bioentities are pervasive in the environment [12-15]. Due to its photoelectric and semiconducting nature, free radical scavenging ability, and anti-cancer and anti-oxidative properties, Se has attracted great attention [12]. Various forms of selenium usually occur, including red-color amorphous selenium $\left(\mathrm{Se}^{0}\right)$, two highly water-soluble forms, i.e., selenate $\left(\mathrm{SeO}_{4}{ }^{2-}\right)$ and selenite $\left(\mathrm{SeO}_{3}{ }^{2-}\right)$, and one in the gaseous form, known as selenide $\left(\mathrm{Se}^{2-}\right)$. Amongst these, the highly toxic form is $\mathrm{SeO}_{3}{ }^{2-}$, which causes an adverse effect on cellular respiration and the antioxidant system, resulting in the inactivation of proteins and hindering the repair of DNA [13,16,17]. Our previous work [18] was focused on the utilization of Pseudomonas aeruginosa for aerobic reduction of $\mathrm{SeO}_{4}{ }^{2-}$ to $\mathrm{Se}^{0}$ using NADPH(Nicotinamide adenine dinucleotide phosphate hydrogen)/NADH(Nicotinamide adenine dinucleotide hydrogen)-dependent selenate reductase enzymes for the fabrication of a nano-biosensor.

In this report, we have endeavored to utilize the selenite-reducing rhizospheric bacteria Stenotrophomonas aidaminiphila to develop a SeNP-based biosensor for optical assessment of heavy metal toxicity. This SeNP-based biosensor was characterized using UV-Vis spectrophotometry, X-ray diffraction 
(XRD), Fourier transform infrared (FTIR), and transmission electron microscopy (TEM). For sensing the toxicity of heavy metals, such as $\mathrm{Cd}, \mathrm{Zn}, \mathrm{Fe}, \mathrm{Hg}$, and As, the fluorescence spectroscopy technique was employed. In this work, a biosensing application was used to analyze the presence of heavy metals in agricultural soil with the help of the selenium-based nano-biosensor, which could be applied for the bioremediation of toxic analytes in the presence of agricultural soil bacterial isolates.

\section{Materials and Methods}

\subsection{Bacterial Growth}

The soil bacteria Stenotrophomonas aidaminiphila has already have been characterized based on 16 SrDNA sequence homology [19]. Cultures were treated with different sodium selenite concentrations $(25,50,75$, and $100 \mathrm{mM})$ in LB (Luria Broth) media for $72 \mathrm{~h}$. The optical density of bacterial suspension was monitored at a wavelength of $600 \mathrm{~nm}$ to determine the cell growth at $28^{\circ} \mathrm{C}$.

\subsection{Biosynthesis of Elemental SeNPs}

The overnight-grown culture in LB broth was transferred to a centrifuge system, and centrifugation was carried out for duration of $10 \mathrm{~min}$ at $5000 \mathrm{rpm}$. A treatment of as-obtained supernatant solution was performed with $2 \mathrm{mM} \mathrm{Na}_{2} \mathrm{SeO}_{3}{ }^{2-}$ and it was, again, incubated at $30{ }^{\circ} \mathrm{C}$ for $72 \mathrm{~h}$. Furthermore, the presence of SeNPs was analyzed by using the red-colored supernatant [18].

\subsection{Characterization of SeNPs}

\subsubsection{X-ray Diffraction Analysis}

X-ray diffraction analysis was performed using the X'pert PRO PANalytical diffractometer with $\mathrm{CuK}_{\alpha}(\lambda=1.54056 \AA)$ in the range of $20^{\circ} \leq 2 \theta \leq 80^{\circ}$ at $40 \mathrm{keV}$ [20]. The $72 \mathrm{~h}$ incubated culture supernatant was lyophilized and converted into fine powder for diffraction pattern.

\subsubsection{Optical Properties (UV-Vis)}

In order to study the color transformation of the bacterial supernatant, the optical analysis was carried out by using a UV-Vis spectrophotometer (Labomed, Los Angeles, CA, USA). The characteristic surface plasmon resonance of the SeNPs was chronicled at various time intervals of $2-72 \mathrm{~h}$ at a wavelength ranging from 200 to $800 \mathrm{~nm}[20,21]$.

\subsubsection{Transmission Electron Microscopic (TEM) Analysis}

For obtaining the size and shape of the SeNPs, carbon-coated copper TEM grids were used for the sample analysis on a transmission electron microscope (TEM; JEOL-JEM-2100F version, Tokyo, Japan) with an accelerating voltage of $80 \mathrm{Kv}$ [18]. The micrograph obtained was utilized for further analysis.

Fourier Transform Infrared (FTIR) Analysis

To study the functional groups present in the SeNPs, FTIR spectroscopic measurement was carried out using a spectrometer (Spectrum 100; Perkin Elmer, Waltham, MA, USA) in the diffuse reflectance mode. Pellets for the measurements were prepared by using the powder mixed with potassium bromide $(\mathrm{KBr})$ at a weight ratio of 1:100, and the spectrum was recorded between wavenumbers of 400 and $4000\left(\mathrm{~cm}^{-1}\right)$.

\subsubsection{Fluorescence Measurements}

Fluorescence studies of the culture supernatant were performed using a spectrofluorophotometer (RF5301PC; Shimadzu, Japan) and the spectra were recorded at a wavelength ranging from 290 to $380 \mathrm{~nm}$ [18-23]. The untreated supernatant and those treated with $5 \mu \mathrm{g} \mathrm{mL}^{-1}$ of $\mathrm{Cd}, \mathrm{Hg}, \mathrm{As}, \mathrm{Zn}$, and Fe were measured with $5 \mathrm{~nm}$ slits and a $280 \mathrm{~nm}$ excitation wavelength. 


\subsubsection{Heavy Metal Toxicity Assessment}

The 100-mL overnight-grown culture in LB medium was centrifuged, and the supernatant was obtained at $5000 \mathrm{rpm}$ for $10 \mathrm{~min}$ and treated with heavy metals. In each flask, heavy metals, viz. Cd, $\mathrm{Hg}$, As, $\mathrm{Zn}$, and $\mathrm{Fe}$, at a concentration of $5 \mu \mathrm{M}$ were added. The flasks were incubated at $37^{\circ} \mathrm{C}$ for $24 \mathrm{~h}$. Then, $20 \mathrm{mM}$ of $\mathrm{Na}_{2} \mathrm{SeO}_{3}{ }^{2-}$ solution was added to the collected supernatant after centrifuging at $8000 \mathrm{rpm}$ for $15 \mathrm{~min}$. The mixture was further incubated at $37^{\circ} \mathrm{C}$ for $48 \mathrm{~h}$. For quantitative assessment, inhibition in the reduction process was evaluated and the color intensity of the treated samples was compared with the control. A bacterial supernatant without treatment with sodium selenite was used as the control.

\section{Results and Discussion}

\subsection{Selenite Tolerance}

Selenium is a vital element for living organisms, viz. microorganisms and humans. It plays a key role due to its presence in macromolecules. To examine the effect of selenite, the bacteria strain was monitored up to $100 \mathrm{mM} \mathrm{Na}_{2} \mathrm{SeO}_{3}{ }^{2-}$ in LB media (Figure 1). After $16 \mathrm{~h}$ of exposure to selenite, the development of red cells started. The data revealed bacteria growth at an increasing concentration of selenite, which did not impede the bacterial growth after $72 \mathrm{~h}$ of incubation.

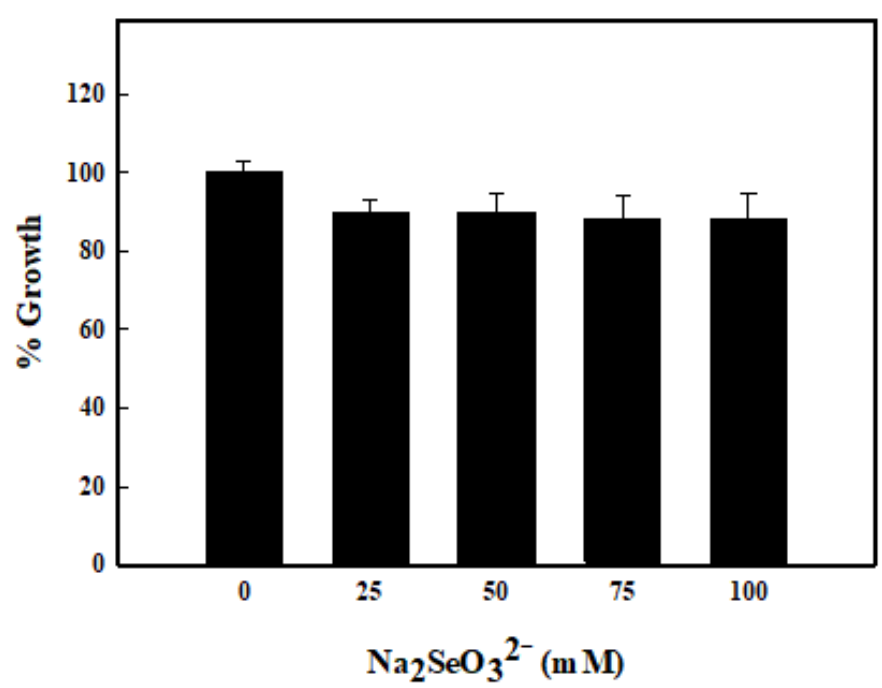

Figure 1. Selenite resistance by Stenotrophomonas acidaminiphila. The experiment was performed in triplicate.

\subsection{Biosynthesis of SeNPs Using Bacterial Supernatant}

Bacterial synthesis, as compared to physical and chemical methods, is easier, does not require any precise conditions, and also helps to achieve greater reproducibility. Biological synthesis also reduces the toxicity and health hazards caused by chemicals used in different processes in chemical synthesis. In order to confirm the formation of nanoparticles, changes in optical density at different time intervals were monitored for SeNPs in culture supernatant with $2 \mathrm{mM} \mathrm{Na}_{2} \mathrm{SeO}_{3}{ }^{2-}$ solution (Figure 2). A strong absorption band positioned at $520 \mathrm{~nm}$, which originates from the surface plasmon resonances of selenium nanoparticles, was observed. Furthermore, the symmetric plasmon band implied that no significant agglomeration of the prepared nanoparticles occurred under the optimum reaction conditions. Spectra of the surface plasmon resonances of SeNPs in the supernatants were recorded periodically at 24,48 , and $72 \mathrm{~h}$ in the wavelength range of $400-650 \mathrm{~nm}$ (Figure 2). The presence of the dark red supernatant designated the reduction process of bacterial metabolite, ensuring the development of SeNPs. The red color of the bacterial supernatant is due to the NADH-dependent 
reduction of selenate into elemental selenium. The enzymatic process is responsible for the change in selenium characteristics. Dwivedi et al. [18] also confirmed the role of nitrate reductase enzyme in the biosynthesis of metal nanoparticles. Hunter and Manter [24,25] have also reported the Pseudomonas sp.-based reduction of selenate.

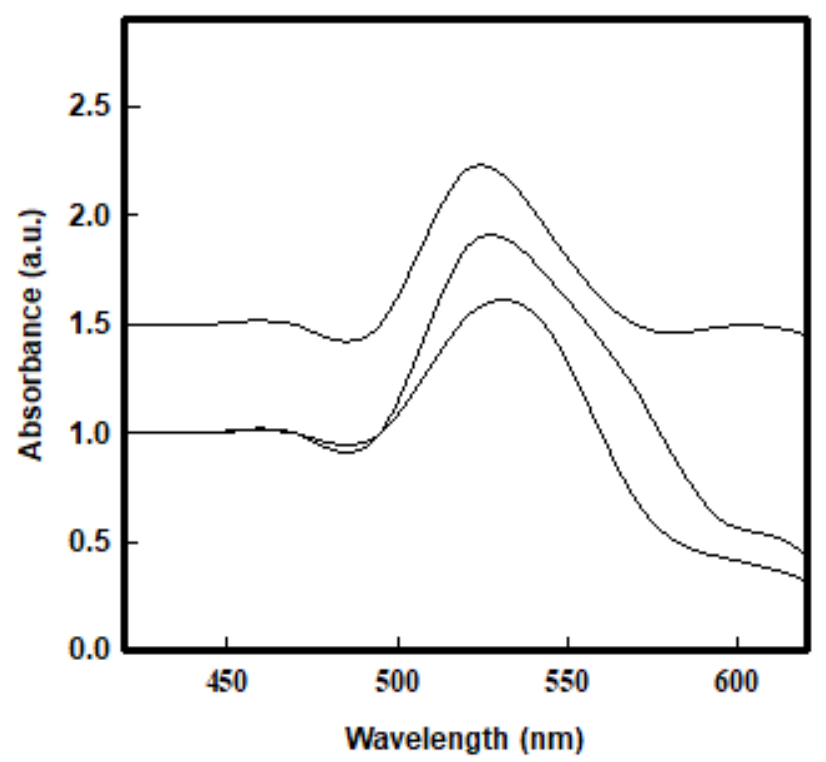

Figure 2. Room temperature UV-Vis absorption spectra of selenium nanoparticles (SeNPs). The arrow indicates the increasing trend of SPR (Surface Plasmon Resonance) bands at an incubation of 24, 48, and $72 \mathrm{~h}$.

\subsection{Characterization of SeNPs}

The synthesized SeNPs were characterized using state-of-the-art techniques. Lyophilized SeNP powder was utilized for the analysis. It can be seen from the XRD patterns of lyophilized SeNPs (Figure 3) that the obtained SeNPs have a crystalline nature with a face-centered cubic (FCC) structure. The diffraction peaks positioned at angles of $23.83^{\circ}, 31.64^{\circ}, 45.40^{\circ}, 56.5^{\circ}, 66.25^{\circ}$, and $75.22^{\circ}$, indexed using Powder X software, were found corresponding to the (100), (101), (102), (112), (210), and (301) planes, respectively. The crystallite size of the NPs was calculated by using the high-intensity peak for the (101) plane and their corresponding full-width at half-maximum (FWHM). The crystallite size of SeNPs, calculated using Scherrer's equation, was obtained to be $\sim 32 \mathrm{~nm}$. The sharp intensity peaks, as shown in the XRD patterns, indicated that the SeNPs have high crystallinity and a single-phase nature. No other phase of impurity was detected within the detection limit of XRD. Figure 4 depicts the TEM micrograph of the SeNPs. It can be clearly seen from the TEM image that the SeNPs were uniform and spherical in shape. Furthermore, SeNPs were distributed all over the surface with some degree of agglomeration, which might be due to the smaller size of the particles. In order to study the size of SeNPs and their distribution, randomly chosen particles were selected. The average particle size calculated by Image J software using the TEM image was in the range of 35-40 nm. These results are in close agreement with the size obtained from XRD studies. Due to the better dispersibility and the higher surface to volume ratio of SeNPs, the nanoparticles help in analyzing target molecules during biosensing. The FTIR analysis of SeNPs synthesized using bacterial metabolites is shown in Figure 5 . The FTIR analysis characterized the surface chemistry of selenium nanoparticles. The stretching vibrations obtained were plotted as \% transmittance in the $\mathrm{x}$-axis and wavenumber $\left(\mathrm{cm}^{-1}\right)$ in the $y$-axis. The data revealed the peaks of metabolites given the impressions at 1645 and $2065 \mathrm{~cm}^{-1}$. The peak at $2065 \mathrm{~cm}^{-1}$ shows alkyne stretching vibrations. The broad peak between 3100 and $3500 \mathrm{~cm}^{-1}$ in the spectrum is designated to the $\mathrm{O}-\mathrm{H}$ group [18]. The characterization data revealed the bioreduction process and validate the formation of SeNPs at ambient temperature and pressure. 


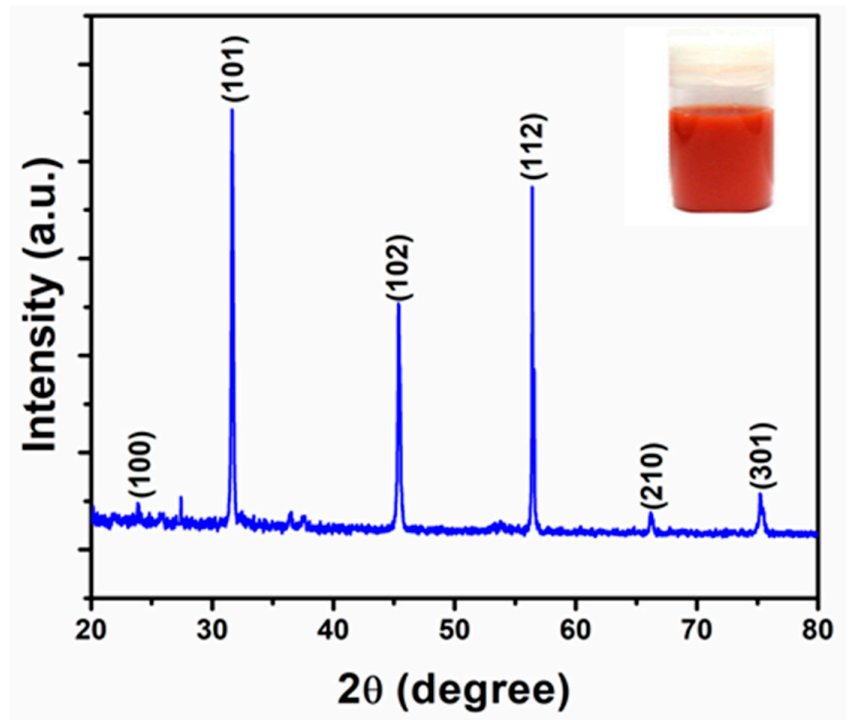

Figure 3. XRD pattern of the prepared SeNPs.

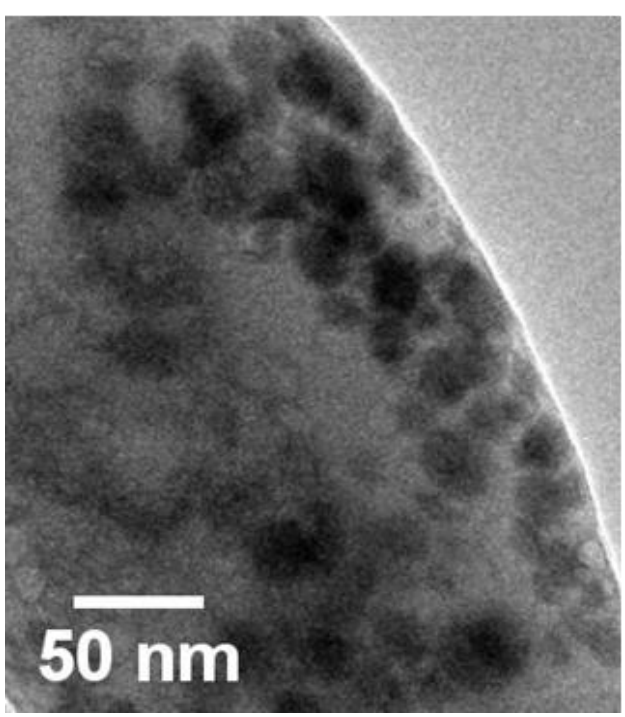

Figure 4. TEM image of the prepared SeNPs.

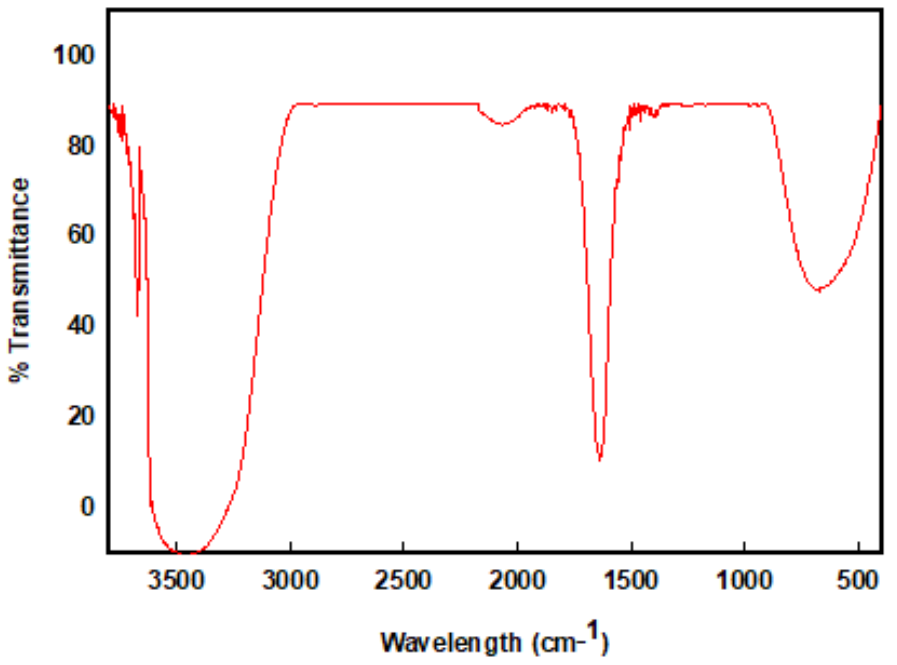

Figure 5. FTIR analysis of SeNPs synthesized using bacterial metabolites. 


\subsection{Fluorescence-Based Assay}

Fluorescent-based biological sensors with better sensitivity and quick and high selectivity are utilized for different diagnostics applications, toxicity assessments, and environmental monitoring. The assay for toxicity detection based on the reduction of selenite wsa used for optical assessment of heavy metal toxicity. NADH reductase-dependent synthesis of SeNPs is used as a biosensor for the analysis. The characteristic fluorescence spectra of NADH were utilized for the detection of enzymatic activities. Figure 6 Panel A reveals a reduction in fluorescence intensity, which confirms the differential toxicity of heavy metals. Inhibition of enzymatic reduction (Figure 6 Panel B) by $6 \%, 9 \%, 40 \%, 49 \%$, and $60 \%$ was observed in the presence of $5 \mu \mathrm{M}$ of $\mathrm{Fe}, \mathrm{Zn}, \mathrm{Cd}$, As, and $\mathrm{Hg}$, respectively, compared to the control. The results in the present study are also in good agreement with previous findings [26-29]. The fluorescence sensing confirmed the decrease in the formation of SeNPs. Due to high sensitivity and simplicity, in recent years, fluorescence spectroscopy has been extensively used for the detection of transition and heavy metal ions.
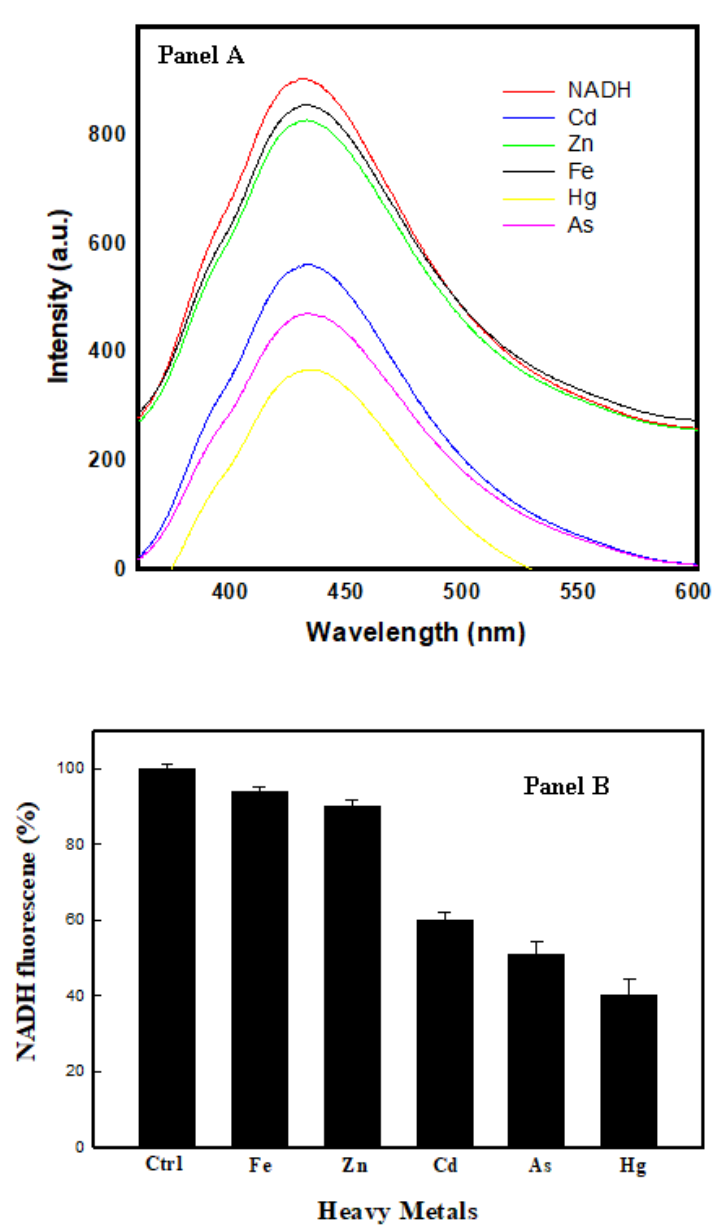

Figure 6. (Panel A) Fluorescence spectra of NADH (Nicotinamide adenine dinucleotide hydrogen) alone and treated with different heavy metals (5 M). (Panel B) Inhibition of fluorescence in the absence and presence of toxic metals.

Fluorescence sensing is based on analyte-induced changes in the physicochemical properties of fluorophores, including fluorescence intensity, lifetime, and anisotropy, which are related to charge transfer or energy transfer processes [30]. Designed for nanomaterial-based fluorescent assays for enzyme activity, various sensing mechanisms were reported, including inner filter effect (IFE), Förster resonance energy transfer (FRET), photo-induced electron transfer (PET), static quenching effect (SQE), and dynamic quenching effect (DQE) [30]. Ono et al. [31] reported the development 
of FRET sensors for heavy metal detection where they linked an organic dye (fluorophore) and a quencher to two ends of a molecular beacon, which resulted in a FRET sensor. Their results showed that the presence of $\mathrm{Hg}^{2+}$ ions induced a hairpin structure, which brought the quencher close to the fluorophore and thus enabled the FRET process, leading to fluorescence-quenching of the organic dye. In another review research, Tong et al. [29] proposed a PET-based fluorescent assay for enzyme activity using quantum/carbon dots (QDs/CDs). The authors have mentioned that during the PET process, QDs/CDs always serve as electron donors, while quenchers, which could be the substrate, and enzymatic products act as the electron acceptors. Additionally, the nature of the linkage of QDs/CDs with quenchers resulted in intermolecular PET and intramolecular PET.

Alternatively, colorimetric detection of $\mathrm{Hg}^{2+}$ ions using AgNPs was reported by Sulistiawaty et al. [32]. In another study, Bobik et al. [33] utilized iron oxide $\left(\mathrm{Fe}_{2} \mathrm{O}_{3}\right) \mathrm{NPs}$ for the adsorption of various heavy metal ions, including $\mathrm{Cu}^{2+}, \mathrm{Ni}^{2+}, \mathrm{Pb}^{2+}, \mathrm{Cd}^{2+}, \mathrm{Zn}^{2+}, \mathrm{Cr}^{3+}$, and $\mathrm{Cr}^{4+}$. For the preparation of $\mathrm{Fe}_{2} \mathrm{O}_{3}$ $\mathrm{NPs}$, the chemical co-precipitation method was used, and parameters, including temperature and volumes of ammonia, were varied, which showed different adsorption capacities for the $\mathrm{Cu}^{2+}, \mathrm{Ni}^{2+}$, $\mathrm{Pb}^{2+}, \mathrm{Cd}^{2+}, \mathrm{Zn}^{2+}, \mathrm{Cr}^{3+}$, and $\mathrm{Cr}^{4+}$ ions. The results in the present study show that the prepared SeNP(using a biogenic approach) based biosensor for the detection of heavy elements could be employed as an effective and environmentally safe future biosensor. This method can be applied for the preparation of various nanostructures and their successful utilization in heavy metal detection.

\subsection{Assessment of Toxicity Biosensor}

The change in color from pale yellow to red confirmed the activities of reducing enzymes present in culture supernatant which convert $\mathrm{SeO}_{3}{ }^{2-}$ to $\mathrm{Se}^{0}$. It was observed that supernatant without any analyte resulted in an enhanced red color, which might possibly be due to the improvement in selenate reduction. Optical analysis of supernatant with toxic heavy metals confirmed the reduction in $\mathrm{SeO}_{3}{ }^{2-}$, which shows a decline in color intensity as compared to the control (Figure 7). The data validate the toxicity of different heavy metals used in this study. However, heavy metals exist in the environment at varying concentrations, and the dosage used may be within allowable limit for some but too high for other heavy metals. Thus, due to optical reduction, the toxicity platform could be utilized for the screening of various xenobiotics. This ecofriendly and easy-to-use method will be helpful in detecting environmental toxicant-comprising heavy metals, pesticides, and nanoparticles through rigorous toxicity examinations. On evaluation with previous research related to nanoparticle-based heavy metal toxicity sensors, our method is improved and more precise than other methods for sensing toxicity. This bio-based approach is rapid, cost-effective, and does not require precarious steps.

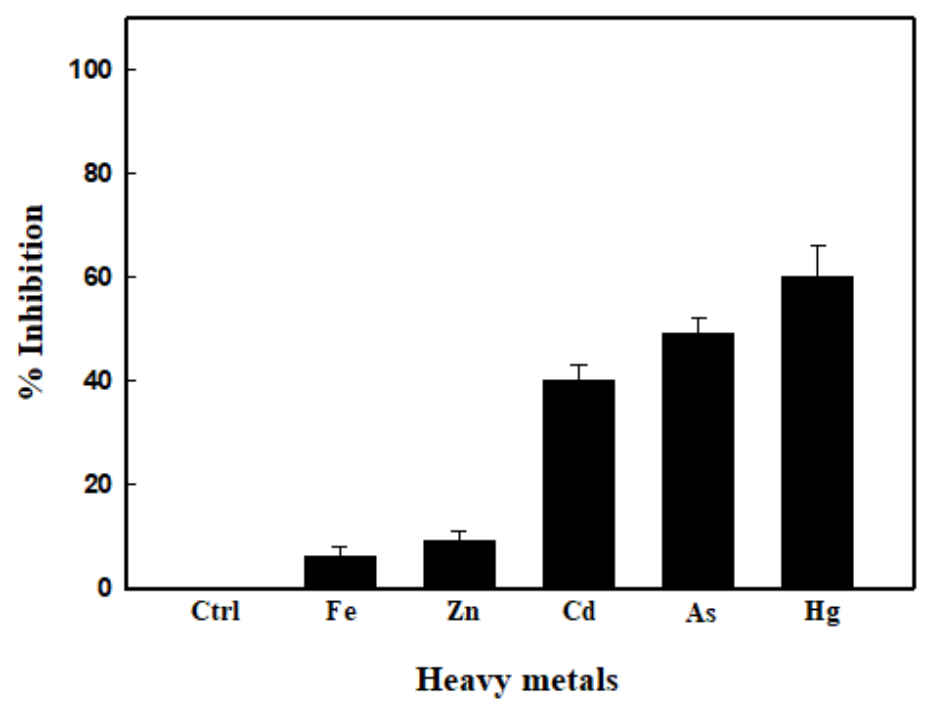

Figure 7. A plot of the percent inhibition of $\mathrm{SeO}_{3}{ }^{2-}$ reduction by heavy metals. 


\section{Conclusions}

In summary, a very rapid, biosynthesized, and ecofriendly agriculture sensor based on SeNPs was developed for the detection of heavy metal toxicity. The SeNPs were obtained with a biologically-assisted method using the NADH reduction process by the $\mathrm{SeO}_{3}{ }^{2-}$-resistant bacteria Stenotrophomonas aidaminiphila and were well-characterized by UV-Vis, XRD, FTIR, and TEM analyses. The bacteria show tolerance to selenite and are capable of reducing $\mathrm{SeO}_{3}{ }^{2-}$ to SeNPs. The optical analysis of the biological synthesis of SeNPs confirmed the formation of the nanostructures with the help of surface plasmon resonance markers. UV-Vis spectroscopy showed a strong absorption band with a maximum at $520 \mathrm{~nm}$, which originates from the surface plasmon resonances of selenium nanoparticles. The increase in absorbance with time confirms the reduction in selenite with SeNPs. The stable SeNPs were further analyzed using XRD, which confirmed the FCC structure with a crystalline nature of the SeNPs. TEM analysis confirmed that the size of the nanoparticles was ranging from 35 to $40 \mathrm{~nm}$, which is in good agreement with the XRD results. The functional groups of bacterial metabolites interacting with SeNPs were analyzed with FTIR. Furthermore, red-colored SeNPs obtained from bioreduction could be utilized as an optical biosensor for heavy metal toxicity assays. The reticence of enzymatic reduction in the presence of heavy metals was measured as a complete toxicity endpoint. The reduction in the color of SeNPs from red to colorless confirms the toxicity of heavy metals. These results suggested that this method could be employed as an economical eco-toxicity assay for prescreening known xenobiotics. Furthermore, the nano-biosensor presented in this work might play a key role in identifying and evaluating environmental contaminants during bioremediation.

Author Contributions: Conceptualization, F.A.; data curation, S.D. and N.A.; methodology, S.D.; validation, F.M.H.; writing — original draft preparation, F.A.; writing—review and editing, F.A., S.D., N.M.S., S.K., N.A., A.A. and F.M.H. All authors have read and agreed to the published version of the manuscript.

Funding: This research was funded by the Deputyship for Research and Innovation, Ministry of Education in Saudi Arabia, IFT20061 and The APC was funded by IFT20061.

Acknowledgments: The authors extend their appreciation to the Deputyship for Research and Innovation, Ministry of Education in Saudi Arabia, for funding this research work through the project number IFT20061.

Conflicts of Interest: The authors declare no conflict of interest.

\section{References}

1. Srivastava, N.; Majumder, C. Novel biofiltration methods for the treatment of heavy metals from industrial wastewater. J. Hazard. Mater. 2008, 151, 1-8. [CrossRef] [PubMed]

2. Li, M.; Gou, H.; Al-Ogaidi, I.; Wu, N. Nanostructured Sensors for Detection of Heavy Metals: A Review. ACS Sustain. Chem. Eng. 2013, 1, 713-723. [CrossRef]

3. Oehme, I.; Wolfbeis, O.S. Optical sensors for determination of heavy metal ions. Microchim. Acta 1997, 126, 177-192. [CrossRef]

4. Verma, N.; Singh, M. A Bacillus sphaericus Based Biosensor for Monitoring Nickel Ions in Industrial Effluents and Foods. J. Autom. Methods Manag. Chem. 2006, 2006, 83427. [CrossRef]

5. Han, S.; Zhu, M.; Yuan, Z.; Li, X. A methylene blue-mediated enzyme electrode for the determination of trace mercury(II), mercury(I), methylmercury, and mercury-glutathione complex. Biosens. Bioelectron. 2001, 16, 9-16. [CrossRef]

6. Aruoja, V.; Dubourguier, H.-C.; Kasemets, K.; Kahru, A. Toxicity of nanoparticles of CuO, ZnO and TiO2 to microalgae Pseudokirchneriella subcapitata. Sci. Total. Environ. 2009, 407, 1461-1468. [CrossRef]

7. Buledi, J.A.; Amin, S.; Haider, S.I.; Bhanger, M.I.; Solangi, A.R. A review on detection of heavy metals from aqueous media using nanomaterial-based sensors. Environ. Sci. Pollut. Res. 2020, 20, 1-9. [CrossRef]

8. Borah, S.B.; Bora, T.; Baruah, S.; Dutta, J. Heavy metal ion sensing in water using surface plasmon resonance of metallic nanostructures. Groundw. Sustain. Dev. 2015, 1, 1-11. [CrossRef]

9. Ravi, S.S.; Christena, L.R.; Saisubramanian, N.; Anthony, S.P. Green synthesized silver nanoparticles for selective colorimetric sensing of $\mathrm{Hg}^{2+}$ in aqueous solution at wide $\mathrm{pH}$ range. Analyst 2013, 138, 4370-4377. [CrossRef] 
10. Walters, F.; Ali, M.M.; Burwell, G.; Rozhko, S.; Tehrani, Z.; Ahmadi, E.D.; Evans, J.E.; Abbasi, H.Y.; Bigham, R.; Mitchell, J.J.; et al. A Facile Method for the Non-Covalent Amine Functionalization of Carbon-Based Surfaces for Use in Biosensor Development. Nanomaterials 2020, 10, 1808. [CrossRef]

11. Devnani, H.; Satsangee, S.P. Green gold nanoparticle modified anthocyanin-based carbon paste electrode for voltammetric determination of heavy metals. Int. J. Environ. Sci. Technol. 2014, 12, 1269-1282. [CrossRef]

12. Zhang, J.; Zhang, S.Y.; Xu, J.J.; Chen, H.Y. A new method for the synthesis of selenium nanoparticles and the application to construction of $\mathrm{H}_{2} \mathrm{O}_{2}$ biosensor. Chin. Chem. Lett. 2004, 15, 1345-1348.

13. Eustice, D.C.; Kull, F.J.; Shrift, A. Selenium Toxicity: Aminoacylation and Peptide Bond Formation with Selenomethionine. Plant Physiol. 1981, 67, 1054-1058. [CrossRef] [PubMed]

14. Lortie, L.; Gould, W.D.; Rajan, S.; Meeready, R.G.L.; Cheng, K.J. Reduction of elemental selenium by a Pseudomonas stutzeri isolate. Appl. Environ. Microbiol. 1992, 58, 4042-4044. [CrossRef] [PubMed]

15. Sabaty, M.; Avazeri, C.; Pignol, D.; Vermeglio, A. Characterization of the Reduction of Selenate and Tellurite by Nitrate Reductases. Appl. Environ. Microbiol. 2001, 67, 5122-5126. [CrossRef]

16. Dong, Y.; Zhang, H.; Hawthorn, L.; Ganther, H.E.; Ip, C. Delineation of the molecular basis for selenium-induced growth arrest in human prostate cancer cells by oligonucleotide array. Cancer Res. 2003, 63, 52-59.

17. Turner, R.J.; Weiner, J.H.; Taylor, D.E. Selenium metabolism in Escherichia coli. BioMetals 1998, 11, $223-227$. [CrossRef]

18. Dwivedi, S.; Al-Khedhairy, A.A.; Ahamed, M.; Musarrat, J. Biomimetic Synthesis of Selenium Nanospheres by Bacterial Strain JS-11 and Its Role as a Biosensor for Nanotoxicity Assessment: A Novel Se-Bioassay. PLoS ONE 2013, 8, e57404. [CrossRef]

19. Dwivedi, S.; Singh, B.R.; Al-Khedhairy, A.A.; Alarifi, S.; Musarrat, J. Isolation and characterization of butachlor-catabolizing bacterial strain Stenotrophomonasacidaminiphila JS-1 from soil and assessment of its biodegradation. Lett. Appl. Microbiol. 2010, 51, 54-60.

20. Dwivedi, S.; Saquib, Q.; Al-Khedhairy, A.A.; Ahmad, J.; Siddiqui, M.A.; Musarrat, J. Rhamnolipids functionalized AgNPs-induced oxidative stress and modulation of toxicity pathway genes in cultured MCF-7 cells. Colloids Surf. B Biointerfaces 2015, 132, 290-298. [CrossRef]

21. Musarrat, J.; Dwivedi, S.; Singh, B.R.; Al-Khedhairy, A.A.; Azam, A.; Naqvi, A. Production of antimicrobial silver nanoparticles in water extracts of the fungus Amylomycesrouxii strain KSU-09. Bioresour. Technol. 2010, 101, 8772-8776. [CrossRef] [PubMed]

22. Patterson, A.L. The Scherrer Formula for X-Ray Particle Size Determination. Phys. Rev. 1939, 56, 978-982. [CrossRef]

23. Wahab, R.; Dwivedi, S.; Khan, M.S.; Al-Senaidy, A.M.; Shin, H.-S.; Musarrat, J.; Al-Khedhairy, A.A.A. Optical Analysis of Zinc Oxide Quantum Dots with Bovine Serum Albumin and Bovine Hemoglobin. J. Pharm. Innov. 2014, 9, 48-52. [CrossRef]

24. Hunter, W.J.; Kuykendall, L.D. Reduction of Selenite to Elemental Red Selenium by Rhizobium sp. Strain B1. Curr. Microbiol. 2007, 55, 344-349. [CrossRef] [PubMed]

25. Hunter, W.J.; Kuykendall, L.D.; Manter, D.K. Rhizobium selenireducens sp. nov.: A Selenite-Reducing $\alpha$-Proteobacteria Isolated from a Bioreactor. Curr. Microbiol. 2007, 55, 455-460. [CrossRef] [PubMed]

26. Lloyd-Jones, G.; Williamson, W.M.; Slootweg, T. The Te-Assay: A black and white method for environmental sample pre-screening exploiting tellurite reduction. J. Microbiol. Methods 2006, 67, 549-556. [CrossRef]

27. Binaeian, E.; Rashidi, A.M.; Attar, H. Toxicity study of two different synthesized silver nanoparticles on bacteria Vibrio Fischeri. World Acad. Sci. Eng. Technol. 2012, 67, 1219-1225.

28. Tomei, F.A.; Barton, L.L.; Lemanski, C.L.; Zocco, T.G. Reduction of selenate and selenite to elemental selenium by Wolinella succinogenes. Can. J. Microbiol. 1992, 38, 1328-1333. [CrossRef]

29. Tong, X.; Shi, S.; Tong, C.; Ali, I.; Long, R.; Zhu, Y. Quantum/carbon dots-based fluorescent assays for enzyme activity. TrAC Trends Anal. Chem. 2020, 131, 116008. [CrossRef]

30. Sauer, M. Single-Molecule-Sensitive Fluorescent Sensors Based on Photoinduced Intramolecular Charge Transfer. Angew. Chem. Int. Ed. 2003, 42, 1790-1793. [CrossRef]

31. Ono, A.; Togashi, H. Highly Selective Oligonucleotide-Based Sensor for Mercury(II) in Aqueous Solutions. Angew. Chem. Int. Ed. 2004, 43, 4300-4302. [CrossRef] [PubMed] 
32. Sulistiawaty, L.; Sugiarti, S.; Darmawan, N. Detection of $\mathrm{Hg}^{2+}$ Metal Ions Using Silver Nanoparticles Stabilized by Gelatin and Tween-20. Indones. J. Chem. 2015, 15, 1-8. [CrossRef]

33. Bobik, M.; Korus, I. Controlled synthesis of iron oxide nanoparticles used as an efficient heavy metal ions adsorbent. In Proceedings of the ECOpole 9, Jarnoltowek, Poland, 14-16 October 2015; Volume 9.

Publisher's Note: MDPI stays neutral with regard to jurisdictional claims in published maps and institutional affiliations.

(C) 2020 by the authors. Licensee MDPI, Basel, Switzerland. This article is an open access article distributed under the terms and conditions of the Creative Commons Attribution (CC BY) license (http://creativecommons.org/licenses/by/4.0/). 